\title{
Prácticas cuestionadas: acusaciones contra los oficiales de la justicia regia en el corregimiento de Murcia y Lorca a finales del siglo XV
}

Recibido: 27/01/2020. Aceptado: 21/05/2020.

\begin{abstract}
Resumen
Este artículo analiza las denuncias sobre los corregidores de las ciudades de Murcia y Lorca, de manera casi permanente a lo largo del reinado de los Reyes Católicos. Si bien se trató de un período marcado por importantes hitos normativos que buscaban moldear la institución del corregimiento, delineando atribuciones y deberes, así como faltas y castigos a las mismas, el proceso era incipiente y coexistía con otras tendencias. La percepción de aranceles, penas y multas que dictaban los corregidores al desempeñar su oficio de justicia da cuenta de esto. Aunque las normas establecían límites a estas prácticas, eran a la vez toleradas, permitidas y alentadas en algunos casos. De la observación de las acusaciones por esta materia y de su tratamiento obtenemos información relevante para caracterizar al corregimiento bajomedieval a través de la práctica de sus agentes.
\end{abstract}

Palabras claves: oficiales de justicia, denuncias, prácticas, regulación, Reyes Católicos.

\section{Questioned Practices: Accusations Against Royal Justice Officers in Murcia and Lorca at the End of the 1sth Century}

\begin{abstract}
This paper analyzes the complaints against the corregidores recorded in the cities of Murcia and Lorca; reports that were a constant during the reign of the Catholic Kings. Although it was a period characterized by a significant development of norms that sought to shape the institution of the corregimiento, outlining its attributions and duties, as well as defining faults and punishments in case of malpractice, this was an incipient process that coexisted with other trends. An example of the last were the tariffs, penalties and fines the corregidores were authorized to enforce while fulfilling their office. Even though the rules set limits to these practices, they were tolerated, allowed and even encouraged in some cases. The study of the accusations
\end{abstract}


on this matter and its treatment will provide us with relevant information to portray the late Middle Ages corregimiento through the practice of its agents.

Keywords: justice officers, accusations, practices, regulation, Catholic Kings.

\section{Introducción}

En las últimas décadas del siglo XV el envío de oficiales regios -en especial de corregidores- a las ciudades castellanas fue parte central del sistema de justicia, a cuya reforma y fortalecimiento se abocaron los Reyes Católicos. Los historiadores de las instituciones estudiaron en profundidad el funcionamiento formal del corregimiento, sus mecanismos de control y los aspectos normativos que lo rigieron (González Alonso, 1970, 2000; Collantes de Terán, 1998; De las Heras Santos, 2019; Quintana Orive, 2012; Riesco Terrero, 2005). Desde las perspectivas más tradicionales, los especialistas consideraron a los corregidores como instrumentos de intervención de la monarquía y resaltaron el rechazo que su llegada originaba en las comunidades urbanas, ya fuera porque representaba un límite a la autonomía concejil, o bien un gasto para las arcas municipales (González Alonso, 2001; López Villalba, 2009; Martínez Peña y Fernández Rodríguez, 2013). Las iniciativas regias -especialmente las de la monarquía católica-, sin embargo, condujeron a la consolidación del oficio (Bermúdez Aznar, 1974). Algunos autores interpretaron la disminución de la resistencia de las ciudades hacia estos agentes como índice de una nueva etapa de autoritarismo regio (Álvarez Álvarez, 2003; Ladero Quesada, 2014), o bien como un efecto del saneamiento de la justicia (Monsalvo Antón, 2005-2006). En cambio, quienes habían visto en el sistema de corregidores un refuerzo del orden público en beneficio de las élites concejiles explicaron el diálogo entablado entre ciudades y corregidores en clave de colaboración (Asenjo González, 2015; Bonachía Hernando, 1998; Del Val Valdivieso, 1995-1995; Diago Hernando, 1993; Guerrero Navarrete, 1994-1995, 2000-2002; Jara Fuente, 2017).

El sistema de corregidores no estaba, sin embargo, exento de conflictos. Estudios concentrados sobre distintas ciudades pusieron de relieve el carácter habitual de su actuación partidista (Diago Hernando, 2004). En general, estos episodios de parcialidad, así como los casos de cohecho fueron considerados desviaciones de las normas, a la luz del instrumental diseñado para combatirlos (Carlé, 1990; Collantes de Terán, 1998; Lunenfeld, 2009). Sin embargo, el lugar concedido a las denuncias y procesos contra estos oficiales regios fue modesto (Carmona Ruiz, 2017; Caselli, 2017a).

Estudios recientes advierten que los corregidores adaptaban su comportamiento a las expectativas y cualidades asociadas a su cargo, que configuran el "habitus del oficial” regio (Brendecke y Martín Romera, 2017). Las acusaciones que recibían no respondían tanto a una realidad, como sí a las estrategias discursivas que tensionaban dicho habitus (Brendecke y Martín Romera, 2017, p. 40). Para Martín Romera, la retórica judicial que afloraba en los juicios de residencia abarcaba ciertos lugares comunes: parcialidad, cohecho, rigor injustificado y negligencia en el oficio eran figuras efectivas para atacar a los corregidores, puesto que ponían en evidencia la ausencia de la necesaria interiorización del habitus del oficio (2018). Asenjo González, en cambio, sostiene que este tipo de denuncias señalaban conductas constitutivas de dicho habitus, al igual que el ejercicio despersonalizado y con competencias definidas del corregimiento (2017). 
Pese a estas consideraciones, los cuestionamientos y acusaciones contra los corregidores, así como el modo de su tratamiento, son facetas que aún ameritan ser exploradas para el período que estudiamos. ¿Eran tan infrecuentes los altercados entre los distintos actores urbanos y los corregidores? Si su presencia había dejado de objetarse en tiempos de los Reyes Católicos, ¿pasaba lo mismo con su actuación? ¿Qué conductas se consideraban lesivas y motivaban denuncias? ¿Se correspondían estas con delitos tipificados en las normas y ordenamientos regios? La atención sobre estas preguntas nos permitirá considerar en qué medida y a través de qué modalidades los corregidores fueron objeto de impugnación, y hasta qué punto dichos cuestionamientos y la forma de procesarlos habilitan la referencia a una esfera de obligaciones y deberes que rigiera la actividad de estos delegados regios. ${ }^{2}$

Los casos de Murcia y Lorca durante el reinado de los Reyes Católicos sirven de base a esta reflexión. Ambas ciudades compartían corregidor -aunque la sede habitual del mismo era Murcia ${ }^{3}$ y gozaron de una importancia vital para la monarquía, lo que explica que Murcia fuera en 1494 una de las primeras ciudades en recibir borradores de los Capítulos para corregidores y jueces de residencia, publicados de manera definitiva y general en 1500 (Losa Contreras, 2003). La relevancia que ya tenía la ciudad como capital del reino se potenció en las últimas décadas del siglo XV (Jiménez Alcázar, 2012, p. 190), al convertirse en base de operaciones para la avanzada militar sobre el reino de Granada. Por su parte, Lorca, la segunda ciudad más poblada del reino (Martínez Martínez, 1985, p. 31) y una villa de frontera cuyo papel fue crucial en el contexto bélico, fue objeto de importantes reformas ordenadas por los monarcas (Molina Molina, 1989). Tanto la guerra como la presencia de un mismo corregidor designado para las dos ciudades permitieron a la monarquía inclinar en su favor la disputa por el control territorial del reino (Molina Molina y Jiménez Alcázar, 1996, p. 53; Hernández Franco y Jiménez Alcázar, 1996, pp. 176-178; Jiménez Alcázar, 2012, p. 189), hasta entonces ostentado por el poderoso linaje nobiliario de los Fajardo (Torres Fontes, 1978).

Los Fajardo habían iniciado su encumbramiento en Murcia apoyados por los soberanos Trastámaras que les permitieron incorporar territorios de realengo a su patrimonio. La constitución de relaciones clientelares con las élites locales, el acaparamiento de oficios concejiles y militares, la ampliación de sus señoríos y el desempeño de las encomiendas de la Orden Militar de Santiago permitieron al llamado "linaje-patrón" hegemonizar el concejo murciano (Molina Molina y Jiménez Alcázar, 1996, p. 54; Hernández Franco y Jiménez Alcázar, 1996, p. 1996; Jiménez Alcázar, 2000-2002). Para comienzos del siglo XV obtuvieron la adscripción hereditaria el Adelantamiento Mayor de Murcia, oficio que tenía cargo del gobierno y la justicia de dicho reino. El poder del Adelantado y sus atribuciones militares le permitían intervenir las jurisdicciones de diversos términos municipales y agredir el dominio territorial de los concejos sobre sus alfoces (Molina Molina y Jiménez Alcázar, 1996, p. 53). Aunque los Reyes Católicos necesitaban conservar su alianza política con los Fajardo y por ello no buscaron degradarlos -al contrario, elevaron su proyección al nivel del reino castellano-, sí operaron para alterar la relación de fuerzas entre estos y los poderes

2 Para advertir esta cuestión resulta útil contrastar las diversas directrices, más o menos delineadas, que recibían los corregidores, con el concepto de "deberes oficiales" desarrollado por Max Weber (1986, p. 168) para dar cuenta de uno de los atributos de la burocracia moderna. Procedentes de las normas y regulaciones administrativas, los deberes oficiales, de carácter impersonal y rutinario estructuran y sujetan la actividad burocrática.

3 Cuando en 1503 Cartagena fue reintegrada al realengo, fueron tres las ciudades que integraban el mismo corregimiento. En él, “el corregidor titular, de manera cotidiana residía en Murcia, y en las otras dos ciudades, Lorca y Cartagena, con la excepción de tener que hacer algo concreto, permanecían en su nombre sendos alcaldes mayores como lugartenientes de corregidor... Las razones de la permanencia más continua en la capital eran obvias, pues desde ahí se tenía la noción de controlar la totalidad del reino, pero es interesante apuntar que este proceso comienza desde el mismo momento de la conquista en el siglo XIII, cuando el propio obispo no ocupa la sede cartaginense en la ciudad que le da nombre a la diócesis y permaneció en Murcia.” (Jiménez Alcázar, 2012, p. 190). 
locales, logrando potenciar a las oligarquías urbanas (Hernández Franco y Rodríguez Pérez, 2009). Es en este clima que encontramos a los oficiales de la justicia regia. Entre ellos, la actuación de los corregidores sirvió a los fines políticos de la monarquía y las élites concejiles, como afirman tantos autores, pero también fue fuente de denuncias y protestas varias.

Como podremos ver, no solo el componente institucional justifica el tratamiento conjunto de las quejas que afrontaron los corregidores y sus oficiales subordinados en Murcia y en Lorca; además, la dinámica que envuelve estos conflictos era similar. Así, encontramos incluso la presentación de peticiones en conjunto de ambos concejos ante la monarquía.

Una primera mirada hacia los cuestionamientos que involucraron a estos corregidores advierte que la promulgación de normativas que regulaban el oficio coincidió con una disminución de pedidos de remoción de oficiales por parte de las ciudades, que solo fueron presentados durante los primeros años del reinado de Fernando e Isabel. ${ }^{4}$ Sin embargo, que los concejos no continuaran rechazando activamente el nombramiento o la prórroga de la designación de corregidores no clausuró la conflictividad en torno de estas figuras. Al contrario, su conducta y actividad fueron permanentemente escrutadas por las élites y los vecinos. Dentro del conjunto de objeciones que recibían, nos concentraremos en este artículo en aquellas que refieran al uso de su función para la obtención de beneficio económico. ${ }^{5}$ Estas actuaciones conflictivas, a las que llamaremos prácticas prebendarias, ${ }^{6}$ incluían el arancelamiento de determinados procedimientos de justicia, la imposición de penas, la percepción de porcentajes sobre las ejecuciones, o la comisión de abusos o irregularidades de distinto signo.

En primer lugar, analizaremos las imputaciones que se fundamentaban en las propias normativas sobre el oficio de justicia. Luego, consideraremos algunos reclamos en los que primaba la percepción de los denunciantes, puesto que se cuestionaban prácticas permitidas por los monarcas. Por último, nos detendremos en las excepciones aprobadas por la Corona frente a algunas denuncias recibidas, exculpando parte del comportamiento de los corregidores. La construcción situacional de las denuncias -es decir, basadas en un recuento pormenorizado de las particularidades del contexto en que tenían lugar- surge como un aspecto destacado que amerita una especial atención (Membrado, 2019).

4 Los corregidores rechazados fueron: García de Alcocer: CODOM (1475-1491), doc. 153, 11 de julio de 1478; doc. 157, 12 de septiembre de 1478; doc. 157, 12 de septiembre de 1478. Lope Sánchez del Castillo: CODOM (1475-1491), doc. 197, 14 de agosto de 1481; AMM, leg. 4280, 35, 28 de julio de $1481-5$ de agosto de 1481. Diego de Carvajal: CODOM (1475-1491), doc. 254, 3 de julio de 1483, p. 476; RGS, leg. 148310, 217, 23 de octubre de 1483. Las fechas de esta lista coinciden con la periodización general que para el conjunto del reino castellano propuso Marvin Lunenfeld. Desde 1474 hasta 1485, las oligarquías urbanas no fueron receptivas a la introducción de corregidores (2009, p. 4): “Even municipalities initially allied with Isabella -which included Aranda, Alcaraz, Carmona, Jerez de la Frontera, Murcia, and Olmedo- laid obstacles in the path of her domination of their internal affairs. The queen's initial choices for corregidor were totally rejected in Murcia, while opposition to corregidores bubbled along elsewhere" (Lunenfeld, 2009, p. 188). Asimismo, estudios concentrados en el caso murciano advierten lo mismo; si bien en una primera etapa los regidores manifestaron rechazo a la presencia de corregidores, con el tiempo esta resistencia se retrotrajo casi por completo (Torres Fontes, 1987, p. 39).

5 Otras imputaciones apuntaban a la parcialidad de los corregidores en el tratamiento de algunos pleitos; a su desempeño irregular a través de dilaciones o de la supresión de ciertos procedimientos; a la omisión de responsabilidades conferidas por la monarquía; y a distintos contubernios con los escribanos. Sin embargo también eran procesados por llevar adelante tareas propias del oficio desde las Cortes de Toledo, como la restitución de términos ocupados.

6 Weber Ilama "prebendalismo" a la administración que llevan a cabo oficiales cuya retribución implica un usufructo económico del oficio pero no su apropiación, por lo que los pagos asignados al funcionario "son bienes separados permanentemente para la seguridad económica del cargo" (Weber, 1986, p. 182). 


\section{Las acusaciones a la luz de las normas}

Aunque el proceso era incipiente, a finales del siglo XV asistimos a la cristalización de algunos atributos y procedimientos que configuraban la praxis de los corregidores. Un conjunto de normas y sentencias judiciales permite vislumbrar los primeros pasos de la conformación de deberes y obligaciones que orientaban su actividad. ${ }^{7} \mathrm{El}$ carácter asalariado del oficio era un rasgo fundamental, y tanto las leyes de Cortes como los Capítulos de 1494 y 1500 preveían multas y castigos por algunas formas de contravención a dicho principio, dictando multas y castigos para ciertas percepciones por fuera del salario. Esto configuraba parte de un repertorio de faltas asimilable a la noción de "delitos tipificados" (Membrado, 2019).

La mayoría de las acusaciones involucraban distintas prácticas prebendarias a través de las cuales los corregidores obtenían sumas extraordinarias de dinero. Este tipo de denuncias cuestionaba directamente una de las piedras de toque del modelo de corregimiento pretendido por la monarquía católica, es decir, su carácter asalariado. Pero si bien el salario era un rasgo destacable, todavía a finales del siglo XV convivía con el arancelamiento de ciertas funciones y la imposición de penas y derechos varios. ${ }^{8}$ Incluso, debido a las dificultades que podían tener las ciudades para solventar el salario del corregidor por medio de repartimientos y propios, "en la composición del ingreso tenían una mayor proporción los recursos derivados de las actuaciones judiciales que el estipendio mismo, el cual pocas veces se veía satisfecho al cien por cien" (Caselli, 2017a, p. 4267). Esta fuente de ingresos fue objeto tanto de conflictos como de valoraciones divergentes. Mientras que algunas conductas eran toleradas y permitidas, otras se denunciaban y suscitaban respuestas generales de los soberanos tendientes a reprimirlas. Era el caso de los reclamos por maravedís y "ropa e otras cosas de ospederia" que los corregidores y sus oficiales exigían para el alquiler de las casas donde posaban. ${ }^{9}$

Otras acusaciones señalaban la imposición inadecuada de penas, que contradecían disposiciones particulares de la monarquía. Por ejemplo, en 1482 los reyes habían ordenado al corregidor Rodrigo de Carvajal que realizara un alarde en Lorca. Los caballeros de premia que fuesen cuantiosos estarían obligados a pagar una multa si no mantenían armas y caballos. Los de menor cuantía o aquellos que ya no se encontraran en condiciones de sostener caballo y armas serían relevados del castigo, en consideración a la "la gran pobreza e falta de pan" que atravesaba la ciudad. ${ }^{10}$ Pese a haber recibido esta indicación, solo válida para aquel caso, los lorquinos denunciaban que el corregidor primero, y el juez de residencia después, ${ }^{11}$ habían prendado a personas "que buenamente no pueden sostener los caballos", respondiendo con

7 Por la pluralidad de derechos y jurisdicciones propia de la sociedad feudal, cuando nos referimos a las normas que regían al corregimiento deben comprenderse al mismo tiempo las leyes de Cortes y pragmáticas, las costumbres y fueros locales, las cartas de comisión que los corregidores recibían y juraban al ser destinados en cada ciudad, así como un conjunto de órdenes específicas que los monarcas les enviaban durante el ejercicio de su función. Para la regulación de las atribuciones del corregimiento, las actitudes y el comportamiento de los corregidores, y los mecanismos para su control fueron centrales en la época: las Cortes celebradas en Toledo en 1480, Cortes de los Antiguos reinos de León y Castilla, IV (1882), Madrid: Real Academia de la Historia [en adelante Cortes de Toledo]; los Capítulos para corregidores enviados a Murcia en 1494 (Losa Contreras, 2003: 242-254) [en adelante: Capítulos para corregidores enviados a Murcia]; los Capítulos para corregidores y jueces de residencia de 1500, editados por Benjamín González Alonso (1970: 299-317) [en adelante Capítulos para corregidores]; y las cartas de nombramiento, caracterizadas por un formulismo regular pero que, en ocasiones, incluían directrices específicas. Además, la literatura de espejos durante el último tercio del siglo XV también jugó un importante rol en la definición de obligaciones y deberes de los corregidores (Hernández Gassó, 2005).

8 Sobre los ingresos que los corregidores obtenían por su actuación judicial ver Elisa Caselli (2017b, p. 230-233).

9 CODOM (1475-1491), doc. 33316 de julio de 1488, p. 625. Los monarcas prohibieron que llevaran maravedís por alquiler, posada o ropa "salvo por su alquiler que les paguen por las casas en que asy estovieren". Esto se castigó también en los Capítulos para Corregidores, p. 302.

10 CODOM (1475-1491), doc. 221, 28 de mayo de 1482, p. 422.

11 CODOM (1475-1491), doc. 242, 29 de marzo de 1483, p. 460. 
excusas y dilaciones frente a los cuestionamientos recibidos por ello. ${ }^{12}$ Los soberanos advirtieron al corregidor que por el incumplimiento de las cláusulas encomendadas podían proceder contra sus bienes. ${ }^{13}$ Sin embargo, no lo hicieron. Se limitaron a reiterar lo requerido en la carta, instándolo a cumplirla al pie de la letra.

Los excesos en la penalización de ciertas conductas también eran objeto de descontento, lo que favorecía un cambiante marco normativo que definía como transgresiones algunas acciones que poco antes se habían promovido -y que poco después se volverían a impulsar-. La vigilancia de las relaciones de mancebía que involucraban a clérigos ejemplifica esto, ${ }^{14}$ ya que era una tarea propia del corregidor, a la vez que una oportunidad para aplicar penas pecuniarias. ${ }^{15}$ La política de la monarquía católica, orientada tanto a reprimir la disolución moral del clero como a fortalecer el honor y su prestigio en las ciudades, había experimentado más de un giro. En las Cortes de Toledo de 1480, los Reyes Católicos volvieron a poner en vigencia leyes establecidas por Juan I, que poco antes habían revocado, reforzando la coerción para asegurar su cumplimiento. Las modificaciones tenían consecuencias directas sobre los procedimientos que debían seguir los corregidores ante denuncias de este tipo: frente a la reiteración del delito, los oficiales de justicia procederían a desterrar por un año a las mancebas y a penalizarlas con el pago de un marco de plata, mientras que la comisión del crimen por tercera vez incluiría, además, cien azotes públicos. ${ }^{16}$ Años después, una pragmática de 1491 admitía que los corregidores actuaban guiados por la codicia "por lleuar para si los maravedis que montan los dichos marcos". ${ }^{17}$ Los clérigos, para evitar la infamia, se dejaban cohechar. ${ }^{18}$ Para poner un límite al descrédito que estas prácticas importaban tanto a clérigos como a corregidores, los monarcas dictaron nuevas disposiciones. A partir de entonces ninguna mujer casada podía ser considerada manceba de clérigo, a menos que su marido la acusara de ello; solo se podría perseguir a mujeres solteras cuya relación de mancebía con los eclesiásticos fuera pública; los corregidores eliminarían el castigo corporal y solo podrían apresarlas si antes las emplazaban, oían y sentenciaban; y, por último, solo podrían allanar las casas de los clérigos cuando las mujeres hubieran recibido una condena. ${ }^{19}$

Pese a estas innovaciones, los oficiales de la justicia regia mantenían otro curso de acción. En 1493, el juez de residencia en Murcia Antón Martínez de Aguilera y sus oficiales fueron denunciados por el deán de la ciudad por haberlo perseguido, espada en mano, hasta el interior de la iglesia en donde se había querido refugiar. ${ }^{20}$ Según el deán, este injuriante arrebato se encuadraba en un conjunto más amplio de deshonras. El juez de residencia prendía a mujeres solteras a las que denunciaba como mancebas de los clérigos, pese a que vivían "honestamente en casas de sus padres e en sus propias casas" y no las encontraba con los clérigos, "ni menos en sus casas". ${ }^{21}$ En la cárcel, las amenazaba con ponerlas bajo tormento -lo que en ocasiones hacíay lograba así hacerlas confesar cosas que no habían hecho. ${ }^{22}$ Gracias a esto, "les a

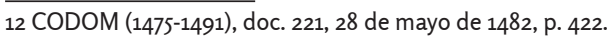

13 Loc. cit.

14 Sobre la política persecutoria contra clérigos amancebados ver Ana Ortega Baún (2018).

15 Cortes de Toledo, ley 71, p. 143-145. Pragmática dada en Sevilla, 21 de mayo de 1491, fol. CXII-CXIII, Libro de Bulas y Pragmáticas de los Reyes Católicos. Juan Ramírez (notario real), Alcalá de Henares, 1503. Capítulos para corregidores enviados a Murcia, cap. 24, p. 248. Capítulos para corregidores, p. 310. Abusos en esta materia de un corregidor en los concejos de Segovia y Trasmiera son analizados por María Antonia Carmona Ruiz (2017, p. 576).

16 Cortes de Toledo, ley 71, p. 144.

17 Pragmática dada en Sevilla, 21 de mayo de 1491, Libro de Bulas y Pragmáticas, op. cit., fol. CXIII.

18 Loc. cit.

19 Loc. cit.

20 CODOM (1492-1504), doc. 93, 11 de mayo de 1493, p. 153.

21 Loc. cit.

22 Loc. cit. 
lleuado e lieua muchos dineros e cohechos,... e diz que haze otros muchos agrauios e syn razones syn les oyr a justicia". ${ }^{23}$ Años más tarde, nuevas pragmáticas volverían a cambiar las premisas con las que se castigaba a los clérigos y a sus mancebas. ${ }^{24}$ Pero en esta ocasión, los monarcas desaprobaron la conducta del juez por incumplir los procedimientos preestablecidos y ordenaron al nuevo corregidor que impartiera justicia a los afectados. No hubo otros apercibimientos destinados de modo particular a Martínez de Aguilera, pese a que, según las imputaciones, había abusado de su autoridad, pervertido las leyes vigentes e impuesto penas indebidas.

La situación fronteriza del reino de Murcia y el contexto bélico, por otra parte, ofrecían motivos de conflicto en relación a la percepción de beneficios pecuniarios por los corregidores. Como señalaba el Consejo Real, "en las cosas de la guerra se fizieron muchos engaños e colusyones e encubiertas en el repartimiento de los dichos peones e otras cosas". ${ }^{25} \mathrm{Y}$ dichos repartimientos estaban a cargo de los corregidores. ${ }^{26}$ Durante 1493 , uno de ellos fue objeto de serias controversias. Quien lo señalaba era un vecino de Lorca, llamado Alfonso Hormi. Según denunciaba, el corregidor Pérez de Barradas había ordenado un repartimiento de peones destinados al cerco de Granada, para el cual "no avia dexado bivda ni huerfano que no prendase e llevase dineros demasyados para conplir". ${ }^{27} \mathrm{Sin}$ embargo, solo había enviado a la guerra a 347 de los 500 peones pedidos y a 50 de los 60 caballeros. Los restantes habían sido encubiertos por el corregidor, que se apropió así de la diferencia de las cuantías. Junto con el contino Pedro de Ayala "se los avia llevado en su bolsa", ${ }^{28}$ para luego aprovecharse de otros auxilios que los monarcas habían ordenado para sus soldados. ${ }^{29}$ Frente a estos abusos, Hormi, personalmente perjudicado, había requerido al corregidor el pago de 400 maravedís y seis reales, a lo que este se había negado. El Consejo Real ordenó al juez de residencia de Murcia oír a las partes involucradas y dictar una sentencia definitiva acerca del dinero que reclamaba el vecino. Pero en cuanto al desarrollo general de la denuncia, salvo una investigación formal de la que no tenemos resultados, no se tomaron otro tipo de medidas.

Otras demandas surgían alrededor de los derechos que llevaban los corregidores en las ejecuciones por deudas (Carvajal de la Vega, 2017)..$^{30}$ Las leyes vigentes en los reinos y las primeras versiones de los capítulos para corregidores permitían recaudar derechos equivalentes al "diezmo de lo que monta la debda principal", a condición de haber sido antes pagada y resarcida la parte acreedora. ${ }^{31}$ Incumplir este procedimiento daba lugar a denuncias como la que el baile general de la ciudad de Orihuela hizo contra el juez de residencia Antón Martínez de Aguilera a principios de 1493. Según relataba, por la ejecución de un contrato por 150.000 maravedís con tres vecinos de Murcia, el bachiller

23 Loc. cit.

24 Los Capítulos de 1500 retomaron y profundizaron los lineamientos de las Cortes de Toledo, Capítulos para corregidores, p. 310. Además: Pragmática dada en Sevilla, 21 de febrero de 1502, fs. CXIII- CXIIII; Pragmática dada en Madrid, 31 de enero de 1503, fs. CXIIII- CXV, Libro de Bulas y Pragmáticas, op. cit.

25 CODOM (1492-1504), doc. 74, 7 de febrero de 1493, p. 121.

26 CODOM (1475-1491), doc. 440, 14 de enero de 1491; doc. 461, 1 de diciembre de 1491.

27 CODOM (1492-1504), doc. 74, 7 de febrero de 1493, p. 120.

28 Loc. cit.

29 Ibid. p. 121-122.

30 CODOM (1492-1504), doc. 147, 6 de noviembre de 1494, p. 245. Cortes de Toledo, ley 53, p. 133: “Quando el creedor pidiere esecucion de alguna deuda de que estouiere pagada alguna parte, ordenamos quel deudor no pague mas derechos déla esecusion, délo que montare lo que verdaderamente deue".

31 Ordenanzas reales de Castilla, libro V, Ley III: Como se deuen fazer las execuçiones por los alguaziles por escusar fruades contra los acreedores; Cortes de Toledo de 1480, ley 50, p. 132. 
le ha llevado XV U [maravedis] diziendo que de derecho de diezmo e execuçion, no lo podiendo ni deuiendo fazer de derecho segund dispusiçion de las leys de nuestros reynos syn que el fuese primeramente pagado de su debda. ${ }^{22}$

El común denominador de todos estos episodios es que las faltas de los oficiales de justicia, aunque no daban lugar a sanciones de importancia, ${ }^{33}$ eran señaladas a la luz del complejo conjunto de normas que estos debían seguir. Como ya se anticipó, esta situación no impedía establecer un margen de excepciones. Veremos en adelante que el apartamiento de dicha normativa no era un requisito excluyente para movilizar el descontento con los corregidores.

\section{Cuestión de rango: denuncias sin transgresiones}

Algunos cuestionamientos que llegaban a instancias regias no se fundaban en la comisión de "delitos" o faltas, sino en la intensidad de prácticas prescritas, o bien, en la percepción que sobre las mismas tenían ciertos sectores de los concejos. En estos casos, las denuncias sobre sentencias, penas y multas que dictaban los corregidores y sus oficiales subalternos no suponían una abierta violación de leyes y disposiciones del reino. En cambio, describían situaciones en las que los corregidores habían ejecutado las tareas propias de su oficio, pero de una manera cuestionable a los ojos de la comunidad.

Era frecuente que los oficiales de justicia se excedieran en la imposición de algunas penas que estaban autorizados a llevar, como las de "carcelaje" y "homecillo". ${ }^{34}$ Las leyes de las Cortes de Madrigal habían actualizado los montos que alguaciles y carceleros llevaban, según el tiempo que pasaran en la cárcel las personas y su condición. ${ }^{35}$ Además, las ordenanzas de la ciudad de Murcia establecían que se debía multar con doce maravedís y encarcelar a quienes anduvieran de noche por las calles, pasada la campana de queda. El castigo era aplicado de modo literal para recaudar la pena en cuestión. En lugar de limitarse a proceder contra los que hallaban "con armas faziendo cosas no deuidas", los alguaciles

muchas vezes prenden a personas forasteras e caminantes que no saben de la dicha hordenança e a moços de poca hedad... e otras vezes a personas de honra que andan syn armas entendiendo en sus negoçios e cosas que les cunple de quien no se presume que anden faziendo delitos, e que a cada vno de ellos diz que llevan los dichos doze maravedis de carcelaje. ${ }^{36}$

En respuesta a la súplica elevada para mitigar el efecto de esta pena, los monarcas mandaron que, en adelante, solo se impusiera una pena de cuatro maravedís "por la guarda de la tal persona". 37 Es decir, no se erradicaba la multa sino que se limitaba su monto.

32 CODOM (1492-1504), doc. 77, 28 de febrero de 1493, p. 127.

33 El modo más habitual de penar errores, negligencias o abusos era que los corregidores pagaran de su bolsillo costas o daños (Caselli, 2017a, p. 4106). Sin embargo, en ninguno de los casos analizados aquí se verifica la concreción de un castigo semejante.

34 Los derechos de “carcelaje” fueron motivo de atención de los Reyes Católicos, debido a "las numerosas corruptelas que se producían en este sentido y que daban lugar al aumento de prisiones y prendas de forma injusta” (Bernal Peña, 2016, p. 28).

35 Cortes de los Antiguos Reinos de Castilla y León, tomo IV, Madrid: Real Academia de la Historia, 1882, Cortes de Madrigal de 1476, p. 49.

36 CODOM (1492-1504), doc. 310, 14 de septiembre de 1499, p. 572.

37 Loc. cit. 
Frente a la sanción que se establecía por la incomparecencia de un reo dentro de los plazos determinados en procesos penales de gravedad, ${ }^{38}$ resultó necesario para el concejo y los vecinos de Murcia que los soberanos reiteraran, en 1492, la limitación del monto que los corregidores estaban autorizados a llevar por tal concepto. La ratificación se volvía indispensable porque anteriormente había sido costumbre en Murcia que los corregidores dictaran penas mayores. En cambio, los reyes ordenaron que se acatara lo dispuesto en 1425 y no se llevara más de 600 maravedís "avnque sean muchos los culpados e en caso de muerte de onbre o de muger e no en otro caso alguno". 39

En 1493, durante el corregimiento de Pedro Gómez de Setúbal, los concejos de Murcia y Lorca solicitaron a los monarcas que, atendiendo a que "la mayor parte [de] la gente de las dichas çibdades es pobre e en los bienes de los mas pobres se fazen las dichas exsecuçiones", ${ }^{\circ}$ pusieran fin a la práctica por la que desde tiempo inmemorial los corregidores llevaban para sí el diezmo de las ejecuciones que hacían. ${ }^{41}$ Los reyes establecieron que a partir de ese momento, en ambos concejos, los oficiales de justicia no llevaran por ejecuciones "de qualquier calidad que sean" más de un maravedí por cada 30 a ejecutar, "avnque fasta aquí acostunbrasedes de lleuar de diez vno". 42 El caso y su resolución ilustran que lo que se percibía como denunciable no era la práctica prebendaria en sí sino que la misma alcanzara un nivel considerado excesivo. Los monarcas no promovían la erradicación de estas actuaciones, frecuentemente permitidas por las leyes, pero sí buscaban adecuarlas a las condiciones tolerables para aquel lugar, en ese momento determinado.

\section{Excepciones y ambivalencias: el otro lado de las atribuciones del corregidor}

Finalmente, si bien reconocían una actuación irregular o agraviante en coincidencia con las normas, las respuestas de los soberanos frente a algunas quejas por el desempeño de sus corregidores atenuaban su condena y establecían excepciones.

Por ejemplo, Diego de Carvajal fue cuestionado en 1482 por arancelar la vista de procesos y el dictado de sentencias, entre otras prácticas por las que ningún corregidor estaba autorizado a imponer derechos según las leyes. ${ }^{43}$ Siguiendo dichas normas y citando su carácter de juez asalariado, los monarcas lo obligaron a restituir lo que hubiera llevado por ese concepto. ${ }^{44}$ No obstante, introdujeron un matiz que limitaba esta orientación, dado que no autorizaban "otros derechos demasyados salvo aquellos que de las leyes e hordenanças de mis regnos podeis e deveis levar". 45 Es visible la impugnación de algunos derechos que los corregidores llevaban, a veces por ser excesivos, pero no siempre se procedía de este modo. Así lo muestra también la reiteración de la denuncia al año siguiente, cuando los monarcas citaron un pasaje de

\footnotetext{
38 Para el cobro de la pena de "homecillo", objeto de variadas interpretaciones y motivo de conflicto entre los corregidores que la dictaban y sus sucesores en el cargo, "era necesario que se cumplieran cumulativamente dos requisitos: que el delito por el que se juzgaba al ausente mereciera pena de muerte, y que en la jurisdicción en la que se veía la causa existiera la costumbre de cobrar este arancel” (Ramos Vázquez, 2005, p. 749-750).

39 CODOM (1492-1504), doc. 59, 20 de diciembre de 1492, p. 97.

40 CODOM (1492-1504), doc. 71, 24 de enero de 1493, p. 117.

41 Loc. cit.

42 Loc. cit.

43 CODOM (1475-1491), doc. 21928 de mayo de 1482, p. 419.

44 Loc. cit.

45 Loc. cit. El destacado es nuestro.
} 
las Cortes de Toledo para reprender el arancelamiento de la vista de procesos. ${ }^{46} \mathrm{Tras}$ la prohibición, el ordenamiento explicitaba que sí quedaban permitidos "los derechos que estovieren hordenamos por la hordenança e costumbre antigua de la çibdad o villa o lugar donde toviere el juzgado". 47

Otros episodios implicaban, al mismo tiempo, procedimientos que permitían a los corregidores la posibilidad de exigir sumas en beneficio propio junto con prohibiciones que limitaban la percepción de derechos. En 1492 Antón Martínez de Aguilera dictó una sentencia a favor de los recaudadores y arrendadores de la ciudad, por cierta mercadería "descaminada" que les correspondía. ${ }^{48}$ Sin embargo, el corregidor lo había hecho a condición de recibir "el diezmo de los dichos descaminados diçiendo que lo avedes de aver e que vos pertenece por las sentençias que en ello days". ${ }^{49} \mathrm{Al}$ reclamo que se sucedió por este motivo, los reyes señalaron que, según las leyes del Cuaderno, el corregidor podría caer en las "penas en que cahen los que lievan derechos que no les pertenecen". ${ }^{50}$ Sin embargo, por la acción de rematar la mercadería, sí estaba habilitado a cobrar derechos previstos por otras leyes:

sy después de dada la dicha vuestra sentencia en el dicho descaminado se pidiere ante vos la esecuçion de lo susodicho por via de sentencia consentida e pasada en cosa juzgada, que de aquella tal esecuçion que asy fizyeredes ayades de llevar e llevedes los derechos que de ello vos pertenecen. ${ }^{51}$

¿Cómo explicar este margen de excepciones sobre aspectos que en otras ocasiones se reprendían? A pesar de todos los ejemplos que hemos visto en los que la monarquía condenaba la imposición de penas y multas por parte de sus corregidores, la justicia de la Baja Edad Media se caracterizó por la proliferación de penas pecuniarias, centrales para el sistema penal y procesal penal (Alonso Romero, 1985). La percepción de derechos, penas y multas a favor de los oficiales de justicia no era unívocamente consideraba delictiva. Al contrario, la participación de estos (y de denunciantes que podían ser personas particulares, pero también los mismos jueces actuando de oficio) en las penas pecuniarias era alentada en numerosas ocasiones como el mecanismo más eficaz de la justicia para garantizar la ejecución de algunas disposiciones (Alonso Romero, 1985, pp. 27-28); es decir, como parte de los "deberes oficiales" de los jueces.

La distribución en tercios de las penas pecuniarias para ciertos delitos era tan habitual a fines del siglo XV que formaba parte integral de los ingresos del corregimiento. ${ }^{52}$ En 1494 los reyes consideraron apropiado, para asegurar que los caballeros de cuantía de Murcia realizaran alardes cada año, que los corregidores llevaran para sí una parte de las penas que castigaban a los infractores. Anteriormente, estas penas se destinaban a la guerra de Granada. Ahora era posible redirigirlas y, así, reforzar la actuación de los jueces. ${ }^{53}$ En la misma línea, la prohibición de importar brocados de oro y plata, así como de decorar y platear elementos de hierro, cobre o

46 CODOM (1475-1491), doc. 256, 18 de julio de 1483, p. 478.

47 Loc. cit. Destacado en el original.

48 Los mercaderes que no pagaban los derechos del almojarifazgo podían ver requisados sus bienes, en concepto de "descaminados", por los arrendatarios y sus agentes (González Arce, 2013, p. 106).

49 CODOM (1492-1504), doc. 48, 13 de noviembre de 1492, p. 82.

50 Loc. cit.

51 Loc. cit.

52 Mientras que en los casos criminales las penas se distribuían por tercios, otros contemplaban la división por mitades. Siempre que el corregidor actuara de oficio, incrementaba su participación en las penas. Como esto provocaba una avidez para dictar este tipo de penas, las leyes establecían que solo podían ejecutarse luego de sustanciado el fallo judicial (Caselli, 2017a, p. 4328).

53 CODOM (1492-1504), doc. 124, 17 de abril de 1494, p. 210. 
latón, era ratificada por una disposición sobre las penas correspondientes, un tercio de las cuales sería "para el que lo condenare e para el secutor que lo secutare".54

La política de punición de los juegos de dados y naipes era más compleja. Formaba parte de las atribuciones de los corregidores, a la vez que configuraba un escenario en el que los reyes actuaban de acuerdo a la casuística, a veces permitiendo y a veces sancionando sus prácticas prebendarias. En 1499 habían sido informados de los debates y diferencias acerca de quiénes tenían derecho a ejecutar y llevar las penas de los juegos vedados. Por un lado, la reclamaban los concejos y regidores, para quienes dichas penas correspondían a los propios de la ciudad por uso y costumbre; por otro, algunas personas particulares que aseguraban tener mercedes de los soberanos anteriores $u$ otros títulos que les daban derecho a estas penas.

Por su parte, los corregidores decían que les pertenecían y que "son anexas a los derechos e salarios de vuestros ofiçios". ${ }^{55}$ De esta triple atribución, se generaba una situación caótica:

los vnos dan ynpedimento a los otros e los otros a los otros e con esto diz que muchas de las dichas penas se quedan por exsecutar e otros se esecutan dos vezes, mostrando cada vno de vosotros preuillejos e titulos diversos e alegando vsos e costumbres e dando entendimientos diversos a las leys de los hordenamientos de estos nuestros reynos. ${ }^{56}$

Preocupados por dotar de un marco de coherencia a la diversidad de normas que coexistían con "escuridad e confusyon",57 los monarcas dictaron un criterio ordenador que, sin embargo, se autolimitaba. Por un lado, ordenaban conservar las disposiciones de las Cortes de Toledo, de modo que un tercio de la pena correspondiera a quien hubiera realizado la denuncia y al juez que hubiera entendido en su procesamiento, mientras que los otros dos tercios serían para la cámara y fisco regios. Pero al mismo tiempo, daban un tratamiento casuista al problema, consintiendo en algunos casos la percepción de derechos de ejecución por parte de los corregidores. ${ }^{58}$

\section{Algunas conclusiones}

Hemos visto a lo largo de esta contribución que las numerosas acusaciones que recibían los corregidores por sus prácticas prebendarias no se detuvieron tras la definitiva implantación del corregimiento, ni se formularon solo durante juicios de residencia o pesquisas extraordinarias; el escrutinio sobre este aspecto de su conducta era permanente. Por eso, aunque fuera una institución ya sólidamente establecida en el período analizado, es posible hablar de una tolerancia crítica hacia las prácticas de los corregidores, como una característica que tiñe al oficio en su conjunto.

A su vez, no había un único corpus jurídico que rigiera la actividad de estos jueces y los interpelara por las faltas que pudieran cometer, puesto que seguían operando y siendo actualizadas por los agentes otras fuentes de derecho. A veces las denuncias recogían elementos de Cortes o pragmáticas, pero era frecuente el recurso a las singularidades del caso, apelando a sentencias regias solo válidas para ese contexto. Las

54 CODOM (1492-1504), doc. 327, 6 de noviembre de 1499, p. 621.

55 CODOM (1492-1504), doc. 333, 23 de noviembre de 1499, p. 632.

56 Loc. cit.

57 Loc. cit.

58 Ibid. pp. 632-633. 
críticas formuladas en base a estos diferentes criterios no inhibían el funcionamiento del oficio, no comprometían la posterior carrera de sus oficiales, ni tampoco conducían a sanciones concretas de relevancia, incluso estando bien fundadas según algunos de los parámetros vigentes. ¿Con qué sentido se hacían, entonces? ¿Y qué efecto tenían?

En su mayoría, los cuestionamientos referían a situaciones particulares y cumplían una función de equilibrio en el sistema urbano, al permitir a una parte desfavorecida encauzar su descontento y buscar una reparación. En menor medida, contribuían a delinear atributos y responsabilidades o, por la negativa, delitos -aunque no siempre de validez general para el oficio-. Durante el período estudiado comenzaban a perfilarse parte de los "deberes oficiales" del corregidor, pero el proceso era incipiente, contradictorio y se veía limitado por otras iniciativas y acciones de la misma monarquía. Los corregidores no estaban sujetos a deberes oficiales totalmente consolidados, porque también se regían por disposiciones válidas para situaciones particulares. La práctica cotidiana de los corregidores expresaba este momento transicional. A la vez que acataban las pragmáticas y disposiciones con que los monarcas buscaban moldear el comportamiento de sus oficiales de justicia, podían ignorarlas o introducir cambios o matices al dictar sentencias o imponer penalizaciones.

Estos factores explican la afluencia de denuncias y el tratamiento casuístico de las mismas. Aún se podían cuestionar conductas que no se consideran delictivas en las Cortes y Capítulos, puesto que no había una definición taxativa de qué se juzgaba como tal. Por lo mismo, las denuncias no siempre condujeron a una amonestación. En general, la monarquía católica tendió a acompañar las denuncias contra sus corregidores al mismo tiempo que los mantenía en sus puestos, en lo que configuraba una política flexible y ambivalente. En este sentido, la institución del corregimiento, parte sustancial del proceso de centralización política, con capacidad de movilizar apoyos y canalizar tensiones, no dejaba de ser por ello conflictiva. 


\section{Dibliografía}

"Alonso Romero, M. P. (1985). Aproximación al estudio de las penas pecuniarias en Castilla (siglos XIII-XVIII). Anuario de historia del derecho español, 55, 9-94.

"Álvarez Álvarez, C. (2003). Oficiales y funcionarios concejiles de la Corona de Castilla durante la Baja Edad Media (un largo proceso de intervención regia y oligarquización). En Las sociedades urbanas en la España Medieval. XXIX Semana de Estudios Medievales. Estella, 15 a 19 de julio de 2002 (489-540). Pamplona: Gobierno de Navarra, Departamento de Educación y Cultura.

» Asenjo González, M. (2015). Función pacificadora y judicial de los corregidores en las villas y ciudades castellanas, a fines de la edad media. Medievalista, 18, http://journals. openedition.org/medievalista/107501/06/2015 (Acceso: 09 de enero de 2020).

» Asenjo González, M. (2017). El corregidor en la ciudad. La gestión de su oficio y la construcción del "habitus" a fines del siglo XV y principios del XVI. Studia Histórica. Historia Moderna, 39, 89-124.

» Bermúdez Aznar, A. (1974). El corregidor en Castilla durante la Baja Edad Media (13481474). Murcia: Universidad de Murcia.

» Bernal Peña, J. (2016). Los instrumentos de la justicia. La cárcel murciana durante la Baja Edad Media (1375-1425). Murgetana, 135, 9-38.

» Bonachía Hernando, J. A. (1998). Materiales para el estudio del régimen de corregidores (Burgos, 1458-1465). Cuadernos de Historia de España, 75, 135-159.

»Brendecke, A. y Martín Romera, M. A. (2017). El “habitus" del oficial real: ideal, percepción y ejercicio del cargo en la monarquía hispánica (siglos XV-XVIII). Studia Historica. Historia Moderna, 39, 23-51.

» Carlé, M. del C. (1990). La corrupción en la función pública. Castilla siglo XV. Estudios de historia de España, 3, 131-158.

"Carmona Ruiz, M. A. (2017). Díaz Sánchez de Quesada. Un corregidor al servicio de los Reyes Católicos. Anuario de Estudios Medievales, 47/2, 567-587.

" Carvajal de la Vega, D. (2017). Crédito privado en Castilla a fines del siglo XV. Una introducción a su estudio. Anuario de Estudios Medievales, 47/1, 3-36.

" Caselli, E. (2017a). Vivir de la justicia. Los réditos del oficio de juzgar y su incidencia en las disputas jurisdiccionales (Castilla en la temprana Edad Moderna). En E. Caselli (Coord.), Justicias, agentes y jurisdicciones. De la monarquía hispánica a los Estados Nacionales (España y América, siglos XVI-XIX) (161-196). México: Fondo de Cultura Económica, edición electrónica.

»Caselli, E. (2017b). El antijudaísmo en la administración de justicia ordinaria. El caso de un corregidor castellano de finales del siglo XV. Espacio, tiempo y forma, 30, 221-245.

"Collantes de Terán, M. J. (1998). El juicio de residencia en Castilla a través de la doctrina jurídica de la Edad Moderna. Historia, Instituciones, Documentos, 25, 151-184.

»De las Heras Santos, J. L. (2019). La percepción de las Cortes de Castilla sobre las medidas anticorrupción existentes en los reinados de los Reyes Católicos y de los Austrias Mayores. eSpania [En ligne], 33, http://journals.openedition.org/e-spania/30806 (Acceso: 09 de enero, 2020).

»Del Val Valdivieso, M. I. (1995-1996). La intervención real en las ciudades castellanas 
bajomedievales. Miscelánea medieval murciana, 19-20, 67-78.

» Diago Hernando, M. (1993). Estructuras de poder en Soria a fines de la Edad Media. Valladolid: Junta de Castilla y León.

»Diago Hernando, M. (2004). El papel de los corregidores en los conflictos políticos en las ciudades castellanas a comienzos del siglo XVI. En la España Medieval, 27, 195-223.

»Gomariz Marin, A. (Ed.). (2000). Documentos de los Reyes Católicos (1492-1504), Colección de Documentos para la Historia del Reino de Murcia XX. Murcia: Real Academia Alfonso $X$ el Sabio.

» González Alonso, B. (1970). El corregidor castellano (1348-1808). Madrid: Instituto de Estudios Administrativos.

» González Alonso, B. (2000). Los procedimientos de control y exigencia de responsabilidades de los oficiales regios en el Antiguo Régimen (Corona de Castilla, siglos XIII-XVIII). Anuario de la Facultad de Derecho de la Universidad Autónoma de Madrid, 4, 249-272.

» González Alonso, B. (2001). La reforma de los concejos en el reinado de Isabel. En J. Valdeón Baruque (Ed.), Isabel la Católica y la política: ponencias presentadas al I Simposio sobre el reinado de Isabel la Católica, celebrado en las ciudades de Valladolid y México en el otoño de 2000 (293-313). Valladolid: Ámbito.

» González Arce, J. D. (2013). Los arrendatarios del almojarifazgo de Toledo en el siglo XV. Miscelánea medieval murciana, 37, 99-119.

» Guerrero Navarrete, Y. (1994-1995). La política de nombramiento de corregidores en el siglo XV. Entre la estrategia regia y la oposición ciudadana. Anales de la Universidad de Alicante, Historia Medieval, 10, 99-124.

» Guerrero Navarrete, Y. (2000-2002). Orden público y corregidor en Burgos (siglo XV). Anales de la Universidad de Alicante, Historia Medieval, 13, 59-102.

» Hernández Franco, J. y Jiménez Alcázar, J. F. (1996). Estado, aristocracia y oligarquías urbanas en el reino de Murcia. Un punto de flexión en torno a las comunidades de Castilla. Chronica Nova, 23, 171-187.

» Hernández Franco, J. y Rodríguez Pérez, R. A. (2009). Bastardía, aristocracia y órdenes militares en la Castilla Moderna: el linaje Fajardo. Hispania. Revista de historia, 69/232, 331-362.

» Hernández Gassó, H. (2005). Estructura y composición del Espejo de corregidores y jueces de Alonso Ramírez de Villaescusa. En J. L. Martos Sánchez, J. M. Manzanaro i Blasco y R. Alemany Ferrer (Coord.), Actes del X Congrés internacional de l'Associació Hispánica de Literatura Medieval, Alicante, 16-20 de septiembre de 2003, 2 (865-878). Valencia: Institut Interuniversitari de Filologia Valenciana.

» Jara Fuente, J. A. (2017). Entre el conflicto y la cooperación: la ciudad castellana y los corregidores, praxis de una relación política hasta la monarquía isabelina. Studia Historica. Historia Moderna, 39/1), 53-87.

» Jiménez Alcázar, J. F. (2000-2002). Los parientes e amigos de los unos e de los otros: los grupos de poder local en el reino de Murcia (ss. XIII-XVII). Anales de la Universidad de Alicante. Historia medieval, 13, 6-137.

» Jiménez Alcázar, J. F. (2012). Identificación e identidad en el desarrollo de la memoria histórica: el reino de Murcia y la Edad Media. Historia y Genealogía, 2, 175-199.

» Ladero Quesada, M. A. (2014). Poder político y sociedad en Castilla. Siglos XIII al XV. Selección de estudios. Madrid: Dykinson.

»López Villalba, J. M. (2009). El concejo imparte justicia: cotos de los oficiales locales a 
mediados del siglo XV. Espacio, Tiempo y Forma, Serie III, Historia Medieval, 22, 153-184.

» Losa Contreras, C. (2003). Un manuscrito inédito de los Capítulos de Corregidores enviado al Concejo de Murcia. Cuadernos de Historia del Derecho, 10, 235-255.

» Lunenfeld, M. (2009). Keepers of the City. The Corregidores of Isabella I of Castile (14741504). New York: Cambridge University Press.

» Martín Romera, M. A. (2018). Contra el oficio y contra natura. Parcialidad, sodomía y self-fashioning en los procesos contra Fernando de Vera y Vargas, corregidor de Murcia (1594-1595). Cuadernos de Historia Moderna, 43/1, 157-181.

» Martínez Martínez, M. (1985). La población de la ciudad de Lorca en 1498. Miscelánea medieval murciana, 12, 27-54.

» Martínez Peña, L. y Fernández Rodríguez, M. (2013). La respuesta regia al desorden urbano: la doble naturaleza de los corregidores. En L. Martínez Peña y M. Fernández Rodríguez (Coord.), Amenazas y orden público: efectos y respuestas, de los Reyes Católicos al Afganistán contemporáneo (9-28). Madrid: Asociación Veritas para el Estudio de la Historia, el Derecho y las Instituciones.

" Membrado, S. (2019). Acusaciones, transgresiones y delitos en torno de los oficiales de la justicia regia en el obispado de Ávila (1475-1503). Sociedades Precapitalistas, 9, e035, https://doi.org/10.24215/22505121e035.

» Molina Molina, A. L. (1989). Los regidores del concejo de Lorca. Sus ordenanzas y evolución (1399-1509). Revista de la Facultad de Geografía e Historia, 4, 495-524.

» Molina Molina, A. L. y Jiménez Alcázar, J. F. (1996). La frontera enquistada: el reino de Murcia a fines de la Edad Media. Meridies, 3, 51-6o.

» Monsalvo Antón, J. M. (2005-2006). Percepciones de los pecheros medievales sobre usurpaciones de términos rurales y aprovechamientos comunitarios en los concejos salmantinos y abulenses. Edad Media. Revista de Historia, 7, 37-74.

» Moratalla Collado, A. (Ed.). (2003). Documentos de los Reyes Católicos (1475-1491), Colección de Documentos para la Historia del Reino de Murcia. XIX. Murcia: Real Academia Alfonso X el Sabio.

» Ortega Baún, A. (2018). Luz y oscuridad: apuntes sobre el concubinato de clérigos en Castilla (siglos XI-XV). Hispania, 78/258, 11-38.

»Quintana Orive, E. (2012). Acerca de la recepción del Derecho Romano en las Partidas de Alfonso X el Sabio en materia de responsabilidad de los oficiales públicos en la Baja Edad Media. Precedentes romanos del "juicio de residencia”. Revue internationale des droits de l'antiquité, 59, 355-373.

»Ramos Vázquez, I. (2005). El proceso en rebeldía en el derecho castellano. Anuario de historia del derecho español, 75, 721-754.

» Riesco Terrero, A. (2005). Los oficios públicos de gobierno, administración, justicia y recaudación y los de garantía de la fe documental en la Corona de Castilla a la luz de una disposición de los Reyes Católicos de finales del Siglo XV (a. 1494). Documenta \& Instrumenta, 3, 77-108.

» Torres Fontes, J. (1978). Los Fajardo en los siglos XIV y XV. Miscelánea medieval murciana, $4,108-176$.

» Torres Fontes, J. (1987). Evolución del concejo de Murcia en la Edad Media. Murgetana, 71, 5-47.

»Weber, M. (1986). Ensayos de sociología contemporánea. México: Origen-Planeta. 